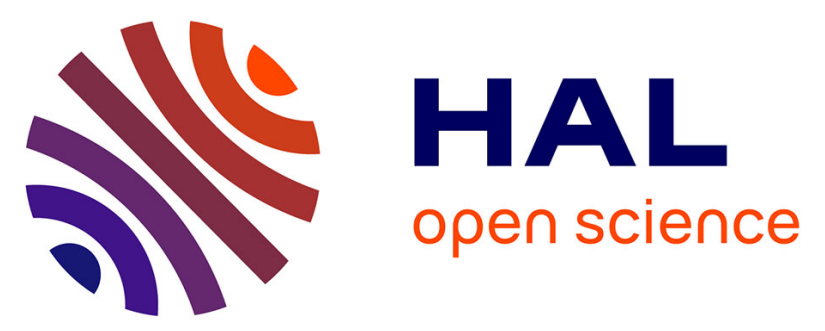

\title{
First step towards a fast analytical method for the determination of biochemical methane potential of solid wastes by near infrared spectroscopy
}

M. Lesteur, E. Latrille, Véronique Bellon Maurel, J.M. Roger, C. Gonzalez, G. Junqua, J.P. Steyer

\section{To cite this version:}

M. Lesteur, E. Latrille, Véronique Bellon Maurel, J.M. Roger, C. Gonzalez, et al.. First step towards a fast analytical method for the determination of biochemical methane potential of solid wastes by near infrared spectroscopy. Bioresource Technology, 2011, 102 (3), p. 2280 - p. 2288. 10.1016/j.biortech.2010.10.044 . hal-00583616

\section{HAL Id: hal-00583616 https://hal.science/hal-00583616}

Submitted on 6 Apr 2011

HAL is a multi-disciplinary open access archive for the deposit and dissemination of scientific research documents, whether they are published or not. The documents may come from teaching and research institutions in France or abroad, or from public or private research centers.
L'archive ouverte pluridisciplinaire HAL, est destinée au dépôt et à la diffusion de documents scientifiques de niveau recherche, publiés ou non, émanant des établissements d'enseignement et de recherche français ou étrangers, des laboratoires publics ou privés. 


\section{First step towards a fast analytical method for the determinationof}

\section{biochemical methane potential of solid wastes by near infrared}

\section{spectroscopy}

M. Lesteur ${ }^{\text {a,b,c }}$, E. Latrille ${ }^{\text {a }}$, V. Bellon Maurel ${ }^{\text {b }}$,J.M. Roger ${ }^{\text {b }}$, C. Gonzalez $^{\text {c }}$, G. Junqua ${ }^{\text {c }}$,

$$
\text { J.P. Steyer }{ }^{a^{*}}
$$

aINRA, UR050, Laboratoire de Biotechnologie de l'Environnement, Avenue des Etangs,

Narbonne F-11100, France

lesteur@supagro.inra.fr ; latrille@supagro.inra.fr; stever@supagro.inra.fr

${ }^{b}$ Cemagref-Montpellier SupAgro, UMR ITAP - Information and Technologies for

AgroProcesses, BP 5095, 34033 Montpellier Cedex 1, France

veronique.bellon@,cemagref.fr; jean-michel.roger@,cemagref.fr

${ }^{c}$ Laboratoire Génie de L'Environnement Industriel, Ecole des Mines d'Alès, 6 avenue de Clavières, 30319 Alès Cedex, France

Gonzalez@ema.fr Junqua@ema.fr

\footnotetext{
* Corresponding author. Tel.: +33 04684251 78; Fax: +33 04684251 60;

e-mail: steyer@supagro.inra.fr
} 


\begin{abstract}
Methane can be produced by the anaerobic digestion of wastes. In order to manage the methane production in anaerobic digester, the Biochemical Methane Potential (BMP) test is the widely applied test to determine their anaerobic biodegradability. It is based on a fermentation process, which is time consuming, about 30 days.

This study aims at investigating the use of near infrared spectroscopy to predict the biochemical methane potential value of municipal solid waste. Near infrared spectroscopy has the advantage to be very fast and applicable to solid waste with a very light sample preparation. Satisfying results were obtained: $\mathrm{R}^{2}=0.76$ and Standard error of prediction $=28 \mathrm{ml} \mathrm{CH} 4 \cdot \mathrm{g}^{-1}$ Volatile Solid, compares very favourably with the reported results for other more expensive and slow methods. To our knowledge, it is the first time near infrared spectroscopy is used to predict the Biochemical Methane Potential value. Using near infrared spectroscopy for waste management would thus lead to a real benefit from an industrial point of view.
\end{abstract}

Keywords : Biochemical methane potential (BMP) prediction; near infrared spectroscopy; biogas; anaerobic digestion; solid wastes

\title{
1 - Introduction
}

In the context of sustainable development, producing energy from solid waste has two major advantages: first, it generates energy (through methane production) and second, it eliminates wastes. Municipal solid wastes are made up of different kinds of waste categories: putrescible matter (kitchen and green waste), papers, cardboard, composite mix (including paper, cardboard, plastic, and aluminium), various textiles, plastics, wood, latex, rubber, incombustible matters 
(rock, faience, oyster shells, glass, metals...) and small particles (<20 mm) (ADEME, 2009). Approximately $63 \%$ of these various fractions, that are potentially digestible by anaerobic digestion could be treated using biological process to extract valuable resource: putrescible matter $(25 \%)$, papers $(15 \%)$, cardboard $(7 \%)$, some textiles (tissue, cotton, diaper, towel) $(9 \%)$ and small particles (7\%) (ADEME, 2009). On the one hand, this makes the municipal solid waste a good source of organic matter to produce biogas, but on the other hand, these various components make municipal solid waste matrix very complex. One serious issue is therefore to characterize the solid wastes before introducing them in the anaerobic digester in order to improve methane production by selecting the most productive wastes and by producing adequate waste mixes.

The Biochemical Methane Potential (BMP) is a commonly used parameter for waste characterization. It determines the quantity of methane $\left(\mathrm{ml} \mathrm{CH}_{4} \cdot \mathrm{g}^{-1}\right.$ Volatile Solid $)$ a waste can potentially produce in anaerobic conditions (Angelidaki et al., 2009; Hansen et al., 2004). This test lasts for long, about 30 days (Hansen et al., 2004), and thus, is not useable as a management tool at industrial scale for anaerobic digestion optimization. Reducing this time could solve the problem of waste stock management and could lead to an increased production of methane by a better control of the fermentation.

Several techniques have already been developed to predict the BMP value faster than with the biochemical way (Lesteur et al., 2010 for a review of these different techniques). The Respiration Index, $\mathrm{RI}_{4}$ (cumulative oxygen consumption in 4 days) and the biogas production index, $\mathrm{GB}_{21}$, a BMP test measured after 21 days of incubation (Scaglia et al., 2010) have been well correlated $\left(\mathrm{R}^{2}=0.89\right)$. These tests are shorter, but still needs considerable time and handling. Accelerating the biodegradation process has also been carried out by the use of enzymes. For instance, in their attempt to assess the biodegradation potential of refuse disposed of in landfills, Rodriguez et al. 
(2005) developed an enzymatic method to evaluate the biodegradability of cellulose compounds (cellulose and hemicellulose) in municipal solid waste. Results correlated well with those obtained with a classical BMP assay ( $\mathrm{R}^{2}$ varied from 0.67 to 0.87 ). The observed discrepancies could be due to the presence of other sources of carbon (lipids, proteins) which are not taken into account with this cellulose-targeted enzymatic method.

Models based on the composition of the waste have also been used for predicting BMP. For instance, the Bushwel formula calculates the BMP values from the elementary chemical composition (C, H, O, N) determined by pyrolysis (Davidsson et al., 2007). The main problem of this formula is that biodegradable and non-biodegradable matter are both taken into account for the calculation, while only the biodegradable matter is metabolized into methane. Therefore, the BMP value is over-estimated. Not only the elementary composition, but also the component composition (carbohydrates, proteins, lipids, fibres, total carbon, total nitrogen) can be input in models. For solid waste, such models have already been built (Gunaseelan, 2007, 2009; Schievano et al., 2009; Mottet et al., 2010) with satisfying performances i.e. Root Mean Square Error of Prediction (RMSEP) of $73 \mathrm{ml} \mathrm{CH}_{4} \cdot \mathrm{g}^{-1} \mathrm{VS}$ and bias of $54 \mathrm{ml} \mathrm{CH}_{4} \cdot \mathrm{g}^{-1} \mathrm{VS}$ (Gunaseelan, 2007). The disadvantages of this method are the time taken to measure all the components of interest and the fact that the correlation is not always very clear, because the composition measurements are not precise for solid wastes. Indeed, some biodegradable molecules could not have been taken into account in the model. More generally, in all the models described here, the BMP value is linked to the global organic matter: the more biodegradable matter, the more methane produced. But using such models with organic matter compounds quantification requires a lot of measurements which are time consuming and costly.

Near Infrared spectroscopy (NIRS) could be a solution for faster measurement. NIRS is an analytical method using the interaction between photons $(1000-2500 \mathrm{~nm})$ and the matter. NIRS 
needs to build a calibration model, generally by means of a training procedure: a calibration set is created and used to find the relationship (i.e. the model) between the spectra and the value of interest. The model is then tested on a test set which does not include the calibration set. NIRS can predict either quantitative (concentrations of products of interest, level of any property) or qualitative data (belonging to a class). NIRS has been widely used to predict organic matter components in several kinds of matrix: fruits and vegetables (Chauchard et al., 2004; Roger and Bellon-Maurel, 2000) and other food products, forages (Stuth et al., 2003) but also complexmatrix products such as soils (Viscarra Rossel et al., 2006). In all these applications, NIR was used to reduce the duration of the composition analysis. Closer to our application, NIRS has also been successful in predicting the digestibility of forages (De Boever et al., 1996) and the production and kinetic parameters of forage digestion (Andres et al., 2005). In the context of anaerobic digestion, NIR has already been used for the on-line monitoring of volatile fatty acids (Jacobi et al., 2009). In our case, one challenge is the complexity of the municipal solid waste matrix and thus the difficulty to build a good predictive model of the BMP value.

NIRS could be used in two ways to approaching the BMP value: on the one hand, directly, by straightforwardly predicting the BMP values from NIR spectra and, on the other hand, indirectly, by predicting the waste composition, values of which will then be used as input in the BMP models. The aim of this paper is to assess the ability of NIRS to directly predict the Biochemical Methane Potential of solid wastes. To our knowledge, it is the first time NIRS is used to determine directly the biochemical methane potential value of wastes.

\section{2 - Materials and Methods}

\section{1 - Samples}


This research was completed with 92 samples, including 68 Municipal Solid Waste (MSW) extracted from a unique plant, but coming from a sorting process, they could be assumed different, 7 MSW extracted from different plants, "raw" waste materials(2 types of cardboard, rice, rusk, potatoes, papers, vegetables, bread and a waste built by mixing some of the simple wastes) and lignocellulosic wastes. These samples were displayed in three sets according to table 1. The BMP statistics of the three sets are shown in table 2 . The calibration set (51 samples) was used to build up the calibration. The test set ( 23 samples) was used to carry out a first validation of the model. The 23 samples were chosen as follows: the 68 MSW samples from the unique plant were ordered by increasing BMP values and 1 over 3 samples was taken for the test set (figure 1). The independent validation set (28 samples) was used to validate the model on quiet different samples (different origins, different scanning date with regard to the calibration set). To avoid block effects, in each of the three sets the samples have not been scanned on the same day: the 68 samples of the MSW from the unique plant have been scanned over 4 days; the 17 green wastes of the independent validation set were scanned the same day; the raw wastes and green waste of the validation set have been scanned the same day; all the others samples have been scanned independently. All the samples were freeze-dried to allow their easy grinding to improve the homogeneity of the final sample. The grinder used was a MF 10 basic IKA WERKE, with a mesh of size 2 .

\section{2 -Characterisation of the samples}

\subsection{1 - BMP test}

The BMP test was carried out in duplicate for each sample. In 0.61 serum bottles, an amount of $1.35 \mathrm{~g}$ of dry matter of sample was digested in mesophilic conditions $\left(35^{\circ} \mathrm{C}\right)$. The inoculum was an active anaerobic sludge. The Inoculum/Substrate ratio was 0.5 . During thirty five days, the 
accumulated gas production was measured every two days with Micro-Gas Chromatography Varian CP4900. The BMP value was the cumulative quantity of methane produced at 35 days. The BMP test method is described in detail in Angelidaki et al.(2009) and Hansen et al.(2004).

\subsubsection{Biochemical characterisation}

All the analysis were performed in triplicate according to standard methods (APHA, 1992). The Van Soest method was used in order to determine soluble and insoluble fractions : Neutral Detergent Fiber (NDF), Acid Detergent Fiber (ADF) and Acid Detergent Lignin (ADL) (Van Soest et al., 1991). Sugars and proteins were respectively analysed using Anthrone and bicinchoninic acid methods (Leyva et al., 2008 ; Ras et al., 2008). Concentration are expressed in equivalent glucose and BSA (Bovine Serum Albumine). Soluble sugars and proteins were obtain after 1 hour of sonication in water. For total sugars, the extraction takes place in sulfuric acid (72\%), in comparaison of the Van Soest methods to extract cellulose part. Total proteins were extracted after 1 hour of sonication in $0.5 \mathrm{M} \mathrm{NaOH}$. Total carbon were determined with the Carbon TOC-V module (Shimadzu). The Nitrogen Total Kjeldahl (NTK) was determined with the BUCHI 370-K.

\section{3 - Near Infrared Spectroscopy}

Solid waste were scanned in reflectance over the $4000-400 \mathrm{~cm}^{-1}$, with a resolution of $4 \mathrm{~cm}^{-1}$, using a spectrophotometer BUCHI NIRFlex N-500 solids fitted with the Petri dish accessory. Spectral units were then transformed into nanometers. The final range is $1000-2500 \mathrm{~nm}$ NIR spectral range, (1500 data points per spectraThe $\log (1 / \mathrm{R})$ pseudo-absorbance spectra were calculated from reflectance (R) spectra. Each sample was divided in three, each part being scanned independently in order to get spectral triplicate per sample. Triplicates were used to 
evaluate the effect of sample homogeneity. Each spectrum was the average of 100 scans in order to reduce the noise. The time required for the 100 scans was around 2 minutes. Ten spectra of one triplicate of 3 different samples were measured and used to evaluate the repeatability of the NIR spectrophotometer.

\section{4 - Data processing and statistical parameters}

Data analysis was performed using PLS Toolbox of Eigenvector Research, INC with Matlab software (@ Mathworks). The Partial Least squares (PLS) method was carried out for building up the model. The following pre-treatments have been tested: Standard Normal Variate (SNV) (Barnes et al., 1989), Detrend (Barnes et al., 1989), first and second derivative, using the Savitsky - Golay algorithm (Savitzky and Golay, 1964) in order to reduce the scattering effect and delete the base line (Zeaiter et al., 2005). Finally, the spectrum were truncated to the $1668-2500 \mathrm{~nm}$ range in order to focus on most relevant ranges. Spectrum truncation was decided after observation of the bcoefficient "spectrum". The b-coefficient "spectrum" is made up of the $p b$-coefficients to be applied to the $p$ absorbance values $A$, i.e. at each wavelength, in the linear combination which delivers the value of interest (here the BMP). Considering the BMP and the absorbance values are centred, a new BMP value is computed as follows:

$$
B M P=\sum_{i=1}^{p} b_{i} \cdot A_{i}
$$

The calibration model was chosen by taking into account the value of the Standard Error of Cross Validation (SECV) and the number of PLS latent variables needed. In case where PLS latent variables was in a rather flat, we also paid attention to the noise of the $b$ coefficient to chose the number of PLS latent variables. This was carried out by observing the $b$ coefficient graph. 
$S E C V=\sqrt{\frac{1}{n_{c}} \sum_{i=1}^{n_{c}}\left(\hat{y}_{i}-\mathcal{y}_{i}\right)^{2}}$

with $\hat{y}_{i}$, the BMP prediction value of the sample $i$ in calibration data set and $y_{i}$, the measured BMP value of sample $i$ in calibration data set, $n_{c}$, the number of samples in calibration data set.

Leave-One-Out Cross Validation was used in order to evaluate the optimal number of latent variables: one sample (triplicates per sample) was taken out from the calibration data set; a calibration was made with the remaining samples and used to predict the sample left out. The loop was repeated with all the samples. Finally, the SECV was calculated.

The model built was then tested on the test set and the Root Mean Square Error of Prediction (RMSEP) and the bias (estimating the systematic error of the NIR method) calculated in order to estimate the quality of the model.

$$
R M S E P=\sqrt{\frac{1}{n_{v}} \sum_{i=1}^{n_{v}}\left(\hat{y}_{i}-y_{i}\right)^{2}} \quad \text { Bias }=\frac{1}{n_{v}} \sum_{i=1}^{n_{v}}\left(\hat{y}_{i}-y_{i}\right)
$$

with $\hat{y}_{i}$, the prediction value of the sample $i$ in test data set and $y_{i}$, the measured BMP value of sample $i$ in test data set, $n_{v}$, the number of samples in test data set.

The values of the Standard Deviation of repeatability (SDr) of both methods were computed as:

$$
\begin{aligned}
& S D r_{N I R}=\sqrt{\frac{1}{n_{t}} \sum \text { Variance }(\text { triplicate of each sample })} \\
& S D r_{B M P t e s t}=\sqrt{\frac{1}{n_{d}} \sum \text { Variance }(\text { duplicate of each sample })}
\end{aligned}
$$

with $n_{t}$, the number of triplicated samples and $n_{d}$, the number of duplicated samples. 
The reproducibility error of the BMP test was calculated. The reproducibility error, SDR, was calculated using 13 repetitions of BMP test with ethanol as a substrate (purity: 96\%; density : 0.81). The measurements were made by two different persons and at different time. Different inocula were also used since the inoculum activity could affect the results. As hypothesis, we put that $\mathrm{SDR}_{\mathrm{BMPtest}}$ is the same for any kind of samples, which is surely not the case, but it would be too time-consuming to make repetitions for each sample. We also have to point out that this reproducibility measurement only deals with the BMP test procedure and does not take into account the sampling error which could be great with MSW. The SDR BMPtest $_{\text {has }}$ been calculated being the standard deviation of the 13 repetitions of ethanol tests.

Standard deviation of reproducibility of NIR model, $\mathrm{SDR}_{\mathrm{NIR}}$ has been calculated, based on 18 measurements of the same sample (sample $44: 231 \mathrm{ml} \mathrm{CH}_{4} \cdot \mathrm{g}^{-1} \mathrm{VS}$ ) at different day, by different people after re-sampling. It is the standard deviation of the 18 predictions of this same sample. This standard deviation allows the computation of the uncertainty limits for a new measurement of BMP. If we make the hypothesis of a Student distribution law, the uncertainty limits for a new prediction are therefore given by multiplying the $\mathrm{SDr}_{\text {BMPtest }}$ by an "enlarging factor", i.e. the Student's law $t_{1-\alpha, d f}, \alpha$ being the significance level of the confidence interval and df the degree of freedom ( $\mathrm{df}$ is equal to the number of reproductions carried out i.e. 2 ). The $\mathrm{t}$-Student is then, $\mathrm{t}_{95 \%, 2}$ $=12.71$. As a consequence, the uncertainty limits for a new BMP test are :

Uncertainty of the BMP test $=\frac{S D r_{B M P t e s t} \times t_{95 \%, 2}}{\sqrt{n}}$ (Widmer-Girod and Staub, 2004).

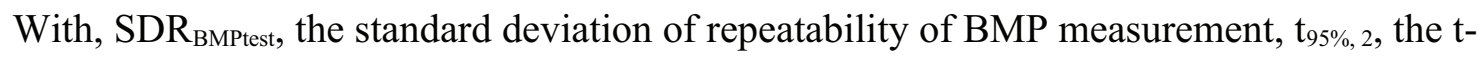
Student and n, the number of samples i.e. 2. 
The uncertainty limits for a NIR-based prediction of the BMP can be computed accordingly.

Uncertainty limits are computed by multiplying an individual standard deviation $s$ by an "enlarging factor", i.e. the $\mathrm{t}-\mathrm{Student}, \mathrm{t}_{1-\alpha, \mathrm{N}-\mathrm{d} f}, \alpha$ being the significance level of the interval, $\mathrm{N}$ the number of samples in calibration and df the degree of freedom (Zhang, 2009). In Multiple Linear Regression, $\mathrm{df}=\mathrm{p}-1$ where $\mathrm{p}$ is the number of variables used for the calibration; in PLS, $\mathrm{df}$ is unknown and lies between the number of factors and the number of wavelengths (Zhang, 2009). Van der Voet, (1999) proposes to compute a pseudo degree of freedom, which in our case is 12. The $\mathrm{t}$-Student is then, $\mathrm{t}_{95 \%, 39}=1.96$. As $s$ is generally unknown, it is first-approximated by the SECV. This means that the true value of a predicted sample will can be found in the confidence interval around the predicted value Yp, i.e. [Yp +/- s.1.96] with a probability 0.95 . Uncertainty of the NIR method : $S E C V \times 1.96$.

The confidence intervals are the best indicators of the accuracy of the measurement.

The Standard Error of the reference method, the BMP test, has been calculated as the ratio between the standard deviation of the 13 samples of ethanol and the number of samples as follow:

$$
S E_{\text {BMPtest }}=\frac{S D R_{B M P t e s t}}{\sqrt{n}}
$$

With n, the 13 samples of ethanol.

In accordance to Dardenne (2010) and to improve the robustness of the model, the calibration and test sets have been joined together and used to calibrate the final model. In order to test the robustness of the model, an independent validation set has been used.

\section{3 - Results and discussion}

\section{1 - Choice of the best pre-treatment process}


The mean biochemical characterisation of $20 \mathrm{MSW}$, equally distributed along the BMP values is presented Table 3. The BMP values of municipal solid wastes and "raw" wastes are presented in Fig. 1. Mean, range and standard deviation values of the calibration, test and independent validation sets are in table 2. Calibration and test sets have a large range of values. Most of the samples are in the range $200-300 \mathrm{ml} \mathrm{CH}_{4} \cdot \mathrm{g}^{-1} \mathrm{VS}$. The values of the test set samples were within the range of the values of the calibration set samples, to avoid extrapolation of the model. As expected, the mean and standard deviation for the calibration and test sets are quite similar, showing that the sample sets are similar. Fig. 2 shows the original spectra in absorbance unit of the MSW and raw wastes. The observation of the MSW spectra shows an homogeneity in their shapes but with no clearly visible peaks. At the opposite, the raw wastes spectra are different with peaks more visible. The main differences between the raw spectra and MSW are in the baseline. The baseline variations, dependent on the wavelengths are mainly due to scattering effects induced by interactions between the particles and the light (Zeaiter et al., 2005). Two baselines are present in NIR range: first one where scattering effects decrease from $1000 \mathrm{~nm}$ to a minimum about $1300 \mathrm{~nm}$ and the second one where scattering effect increase from $1300 \mathrm{~nm}$ to the end of NIR range. In NIRS, the Beer Lambert law is an generally accepted model which reflects the link between the absorbance and the concentration of compounds. Fig. 3 shows the two main scattering effects due to the interactions between the particles and the NIR light : (b) an increasing of the mean path length $(\ell)$, which results in a multiplicative effect ; (c) the lost of photons which results in adding a baseline. It is generally assumed that the multiplicative effect is independent from the wavelength and that the baseline is linearly related to the wavelength. The homogeneity between spectra of calibration and test data sets is a necessary condition to get good prediction. In order to decrease the baseline shift associated to the scattering effect, pre-treatments described in material and methods have been used, i.e. SNV (SNV centers and scales individual spectra, by respect- 
ively row average and row standard deviation), Detrend (detrend deals with subtracting the mean or a best-fit line (in the least-squares sense) from the spectra), first and second derivatives (derivative remove the baseline linear slope variations and additive effects). SNV was carried out first, leading to spectra showing a homogeneous shape for MSW samples and similar shapes for the raw spectra (Fig. 4). Only few parts of the spectra are then slightly different between the raw wastes and MSW (arrows in Fig. 4): peaks which are visible at $1730 / 1765 \mathrm{~nm}$ and $2310 / 2350$ $\mathrm{nm}$ on the MSW spectra are less visible on the raw spectra. In these regions, $-\mathrm{CH}_{2}$ bonds absorb. These $-\mathrm{CH}_{2}$ bonds are often met in lipid and plastic compounds. In raw samples, there is no plastic and lipids are present in low quantity only. MSWs absorb more strongly than the raw wastes in the shorter wavelengths (1000-1200 nm). This could be explained by the darker colour of MSW and their high absorption in the end of visible range close to the low NIR wavelengths.But this difference is not an issue because this part of the spectrum has not been used for the calibration model.

The best pre-treatment tested was with SNV and Detrend applied on the $1668-2500 \mathrm{~nm}$ spectral range (table 4). The model required seven latent variables, which is a reasonably low number, taking into account the complexity of the waste matrix. However, models based on the truncated spectrum and including SNV alone or SNV and first derivatives were also quite good. Spectra pre-treatments allow us to be more precise and improve the robustness by reducing the number of factors.

\subsection{Discussion on the selected model}

Predictions using the best PLS model (model A, 1668-2500nm range, PLS-SNV-Detrend) are presented in Fig. 5. SECV and RMSEP are 31 and $28 \mathrm{ml} \mathrm{CH}_{4} \cdot \mathrm{g}^{-1} \mathrm{VS}$ for respectively calibration and test with $\mathrm{R}_{\text {calibration }}^{2}=0.79$ and $\mathrm{R}_{\text {test }}^{2}=0.76$. Since the work of Faber et al. ( 
For models (A), i.e. including the raw wastes, the difference between calibration and test statistics results are smaller with spectrum truncation than without. Spectrum truncation helps reducing the matrix effect and thus the difference between the raw wastes and MSW spectra. This is verified symmetrically, by considering the difference between calibration and test statistics results, which is smaller when the calibration data set does not include the raw wastes. Spectrum truncation seems to be necessary when very different kinds of wastes are used in the calibration data set.

Raw wastes are mentioned by arrows in Fig. 5, showing the predicted vs true BMP values for both calibration and test sets. For some of them (green waste, mixed waste and potatoes), the prediction (carried out through the cross validation procedure) is not as good as for the MSW ones. As there is only one sample of each raw waste, when this sample is used as the crossvalidation sample, the error may be large and spoils the whole SECV. This is probably due to their differences mentioned above in spectra (Fig. 4). Raw wastes are composed of homogenous organic matter whereas MSW are much complex matrices. The model, mainly trained on MSW spectra, is therefore more suiting MSW spectra than raw waste ones. Taking into account the main variability that occurred in the BMP test (e.g., the initial inoculum activity and the matrix complexity of the municipal solid waste), these results are fully satisfying from a practical pointof-view.

A so-called "Dunne effect" is visible in the predicted vs actual BMP values (Fig. 5): low values are over-predicted and high values under-predicted. This well-known effect comes from the fact that the model is regressed towards the mean (i.e. the mean is a first order estimator of any new sample value). This effect is increased when the factor to be predicted has a Gaussian distribution in the calibration set (Williams and Norris, 2001). This is globally the case here: most samples 
are close to the mean value (230 $\left.\mathrm{ml} \mathrm{CH}_{4} \cdot \mathrm{g}^{-1} \mathrm{VS}\right)$ (Fig. 1). To avoid the Dunne effect, it is recommended to have a uniform distribution in the calibration database. Since the BMP test is very long, no more samples have been tested to amend the sample population distribution. PLS regression has been also made on a calibration set which did not include the raw waste spectra (see B in table 4). The calibration results are much better for the calibration set without raw spectra due to the homogeneity of the database and also due to the fact that three raw samples are in the extrema of the calibration data set. However for the test set, the difference between the two models A and B is almost null. This shows that the models built with or without raw spectra are quite similar and robust with regard to samples different from the MSW but close from a spectra point of view.

\subsection{Validation on independent samples}

A validation have been carried out on independent samples, different from the calibration and test set ones (different products, different origins, different scanning dates). Results of the prediction of these independent samples are shown figure 6. The RMSEP and $\mathrm{R}^{2}$ of this prediction are respectively $80 \mathrm{ml} \mathrm{CH} 4 . \mathrm{g}^{-1} \mathrm{VS}$ and 0.53 . About $50 \%$ of the samples are included in the uncertainty limit of the previously established model. 5 miscellaneous MSW (6 in total) are well predicted, as 3 raw wastes (4 in total). Only 3 (17 in total) lignocellulosic wastes are well predicted. The established model are satisfying for the prediction of the miscellaneous MSW and the raw wastes, but the lignocellulosic wastes are surely too different in composition from the MSW used for the calibration. 
Here we could see the limit of the method. As wastes are very complex and could be different almost to the infinite, 2 ways could be used in order to predict well the methane potential. The first choice is to use homogenous samples (same kind of samples, but different origins, different scanning date) and to use them in a dedicated calibration model. In this way, several calibration models are necessary depending on the number of kind on wastes and this allow accurate prediction. This way supposes to know which calibration model used with a new and unknown sample, which could not evident. Classification procedure will be needed. The second way is to use a global calibration model, with heterogeneous calibration samples (different kind of samples, thus different origins, different scanning date). So, only one calibration model will be get and prediction will be more robust.

These are two different strategies, chosen in terms of the aim of the prediction, very precise or not.

\subsection{Comparison with the method based on the biochemical characterisation}

If we now compare this method with other method of prediction based on the biochemical characterisation found in literature (carbohydrates, proteins, fibres determination), it points that the NIR method is better. Gunaseelan (2007) used homogenous samples categories for the calibration and validation set and really few samples in validation set and get a RMSEP of $91 \mathrm{ml}$ $\underline{\mathrm{CH}}_{4} \cdot \mathrm{g}^{-1} \mathrm{VS}$ (SEP: $73 \mathrm{ml} \mathrm{CH} 4 . \mathrm{g}^{-1}$ VS, bias: $54 \mathrm{ml} \mathrm{CH}_{4} \cdot \mathrm{g}^{-1}$ VS). Gunaseelan (2009) used a new model, and predict sample of the same origin and lignocellulosic samples from previous study and get better results by expanding the validation data base, RMSEP: $66 \mathrm{ml} \mathrm{CH}_{4} \cdot \mathrm{g}^{-1}$ VS (SEP: 65 $\underline{\mathrm{ml} \mathrm{CH}}_{4} \cdot \mathrm{g}^{-1} \mathrm{VS}$, bias: $5 \mathrm{ml} \mathrm{CH}{ }_{4} \cdot \mathrm{g}^{-1} \mathrm{VS}$ ). Whereas Schievano et al. (2009) used heterogeneous $\underline{\text { samples categories (vegetable wastes, sludge, liquid wastes, municipal solid wastes) and didn't }}$ get better results RMSEP: $140 \mathrm{ml} \mathrm{CH}_{4} \cdot \mathrm{g}^{-1} \mathrm{VS}$ (SEP: $134 \mathrm{ml} \mathrm{CH}_{4} \cdot \mathrm{g}^{-1} \mathrm{VS}$, bias: $-42 \mathrm{ml} \mathrm{CH}_{4} \cdot \mathrm{g}^{-1} \mathrm{VS}$ ). 
Author-produced version of the article published in Bioresource Technology, 2011, 102, 3, 2280-2288.

The original publication is available at http://www.elsevier.com/locate/biortech

doi:10.1016/j.biortech.2010.10.044

The used of heterogeneous samples in calibration and validation set seems to decrease the accuracy but increase the robustness of the prediction method. The better prediction by the NIR method could be explain by several raison. NIR is able to analyse the entire organic matter and globally whereas with the biochemical method some molecules could bot be determined. With solid wastes, there could be a lack of accessibility of the matter to the reactant of the biochemical method whereas NIR spectroscopy assess the whole of the organic matter in one measure. Some biochemical determination seem not completely adapted for all the kind of molecules. As example, the Anthrone method for the carbohydrates determination are not as much accurate than the phenol method whereas Anthrone is more commonly used in waste characterisation (Piccolo et al., 1996; Feller et al., 1991). Anthrone method underestimates the concentration of main of carbohydrates as galactose, mannose, xylose, arabinose (Feller et al., 1991). Same conclusion could be found in literature for the protein determination between BCA and Lowry method (Ras et al., 2008). BCA method overestimates the concentration of proteins in sludge, whereas Lowry method, underestimates the concentration (Ras et al., 2008). Furthermore, the error of prediction for model based in biochemical characterisation takes into account a lot of error sources as the error of measurement of the different determination, the error on the sampling procedure and on the sample preparation procedure are taken into account (weighing, extraction step, pipetting $\underline{\text { step) whereas in NIR method, fewer preparation are needed and only the sampling step are really }}$ sources of error in the sample preparation procedure.

\section{5- Discussion on the feasibility of replacing BMP biochemical determination by a NIR prediction.}

Metrological performances 
The first issue is the performance of the NIR-based BMP assessment, with regard to metrological parameters of accuracy, trueness and precision.

In this example, NIR has proven to be true (bias closed to 0) following the metrological definition of trueness i.e. "closeness of agreement between the average of an infinite number of replicate of measured quantity values and a reference quantity value" (see VIM). However, the closeness between SEP and SECV comes from the fact that test and calibration samples come from the same set of samples. A future study with samples coming from absolutely different sites is to be carried out to answer this question. Precision was also considered good for the NIR-based measurement, as shown by the SDr, which is very close to the BMP one, respectively 7 and 10 $\mathrm{ml} \mathrm{CH} 4 \mathrm{~g}^{-1}$ VS (Mean Standard Deviation of the triplicates (BMP) or the duplicates (NIR) measurements, see above 2.4). This is very satisfying for NIR because the standard deviation of the NIR assessment takes into account several error sources as the homogeneity of the waste, the good fitting of the model, the repeatability of the NIR spectrophotometer and the repeatability of the reference measurement i.e. the BMP method. As expected, the repeatability of the NIR spectrophotometer is negligible with about $1.7 \mathrm{ml} \mathrm{CH}_{4} \cdot \mathrm{g}^{-1} \mathrm{VS}$.

If we now deal with accuracy, i.e. "closeness of agreement between measured quantity values that are being attributed to the measurand"' (see VIM), we can compare the confidence limits obtained with the biochemical analysis and the NIR analysis.

The closeness of uncertainty limits of NIR-based and biochemical-based BMP values respectively $61 \mathrm{ml} \mathrm{CH}_{4} \cdot \mathrm{g}^{-1} \mathrm{VS}$ and $65 \mathrm{ml} \mathrm{CH}_{4} \cdot \mathrm{g}^{-1} \mathrm{VS}$ show that NIR is able to predict the BMP value directly, with satisfactory error and faster (few hours, including sample pre-treatment) than the biochemical test. 
The Ratio of Performance to Deviation (RPD) has been calculated in order to evaluate the different calibration models. A RPD of 2.36 has been obtain with the selected calibration. It is somehow satisfying but justifies the need of improvement of the calibration (Williams, and Sobering, 1993). By expanding the number of samples in the calibration data base, the prediction should be improved (Williams and Norris, 2001). The extension of the model to other kind of wastes is possible if a database of the different kinds of wastes is available including their spectra and BMP value associated. This method is applicable to any kind of waste: municipal solid waste, solid waste from agro industrial and agricultural products and also municipal sludges. Table 5 summarises the main outputs. The average of the predicted values of the test set $(223 \mathrm{ml}$ $\left.\mathrm{CH}_{4} \cdot \mathrm{g}^{-1} \mathrm{VS}\right)$ are very close to the average of the true values $\left(227 \mathrm{ml} \mathrm{CH}_{4} \cdot \mathrm{g}^{-1} \mathrm{VS}\right)$. The prediction does not present any bias. The spectrophotometer is reproducible since these 2 data sets have been scanned in 4 different days.

\section{Practical implementation}

To have a representative BMP test results, it is necessary to grind the samples in order to improve their homogeneity. Grinding requires samples to be dried. In our case, this has been carried out after freezing and drying. In the NIR spectroscopy, using dry samples is more efficient because it removes water which strongly absorbs in the NIR range. But freezing and drying are time consuming (more than 24 hours) and need special devices. The freezing and drying procedure could be substituted by oven-heating at around $60^{\circ} \mathrm{C}$ for several hours until municipal solid waste only contain 5\% moisture left. The grinding step could be also avoided, provided that the heterogeneity of the sample is captured in the NIR spectra. Using an adequate measurement method, which does not require sample preparation, it could be possible to replace the triplicate measurement made after grinding by numerous measurements directly on the waste. Taking 
numerous NIR measurements on the same sample would allow us to build a representative database of the waste without grinding. Another solution could be to use hyperspectral camera to have a global image of the waste, where each pixel is composed by a spectrum (Gorretta et al., 2006; Bellon Maurel and Dubois, 2009).

The main innovative point is the benefit of the short time spent to analyse the waste. The analytical time drops from several weeks with the biochemical test to few hours with NIRS (including sample pre-treatment). It will allow a faster evaluation of the quality of the waste and the methane production in industrial anaerobic digester would be improved. Moreover the stock management of the waste will be easier and faster and the risk to degrade a low digestible waste and to loose the micro-organisms population will be decreased. The co-digestion would be also improved by a better selection of the quality of degradation of the waste. In the future, codigestion would be managed by NIRS to determine what waste mixtures are the most appropriate. The co-digestion of a low digestible waste and a high digestible waste would be better controlled.

\section{4. - Conclusion}

In this paper, our objective was to predict the Biochemical Methane Potential (BMP) value of Municipal Solid Wastes (MSW) and other organic wastes using Near Infrared (NIR) Spectroscopy. The BMP value was well predicted, with a RPD of 2.36 and a RMSEP of 28 $\mathrm{mlCH}_{4} \cdot \mathrm{g}^{-1}$ VS. The standard deviation of repeatability of the NIR measurement was close to the one of the BMP test, respectively 10 and $7 \mathrm{ml} \mathrm{CH}_{4} \cdot \mathrm{g}^{-1} \mathrm{VS}$. The limit of uncertainty of prediction was as the same order in the NIR than the biochemical test, respectively 61 and $51 \mathrm{ml} \mathrm{CH}_{4} \cdot \mathrm{g}^{-1}$ VS.

\section{Acknowledgement}


Authors wish to acknowledge financial support for this work from Languedoc Roussillon

Regional Council (Ecotech platform) and ILEE (Institut Languedocien de recherche sur l'Eau et

l'Environnement).

\section{REFERENCES}

ADEME. French national household waste characterization survey. French Environnment and Energy Management Agency (ADEME). (2009).

Andres, S., Calleja, A., Lopez, S., Gonzalez, J.S., Rodriguez, P.L., Giraldez, F.J., 2005.

Prediction of gas production kinetic parameters of forages by chemical composition and near infrared reflectance spectroscopy. Anim. feed sci. technol. 123, 487-499.

Angelidaki, I., Alves, M., Bolzonella, D., Borzacconi, L., Campos, J.L., Guwy, A.J., Kalyuzhnyi, S., Jenicek, P. and van Lier, J.B., 2009. Defining the biomethane potential (BMP) of solid organic wastes and energy crops: a proposed protocol for batch assays. Water sci. Technol. 59, 927-934.

APHA (1992). Standard methods for the examination of water and wastewater, $18^{\text {th }}$ ed. American Public Health Association, Washington, D.C.

Barnes, R., Dhanoa, M., and Lister, J., 1989. Standard Normal Variate Transformation and Detrending of Near-Infrared Diffuse Reflectance Spectra. Appl. Spectrosc. 43, 772-777.

Bellon Maurel, V., Dubois, J., 2009. Near-infrared Hyperspectral Imaging in Food and Agricultural Science in: Salzer, R., Siesler, H.W. (eds.), Infrared and Raman Spectroscopic Imaging. Wiley-VCH, Allemagne, pp. 259-376.

Chauchard, F., Cogdill, R., Roussel, S., Roger, J.M. and Bellon-Maurel, V., 2004. Application of LS-SVM to non-linear phenomena in NIR spectroscopy: development of a robust and portable sensor for acidity prediction in grapes. Chemometr. intell. lab. syst. 71, 141-150.

Dardenne, P., 2010. Some considerations about NIR spectroscopy: Closing speech at NIR-2009. J. near infrared spectrosc. $21,1,8-14$

Davidsson, A., Gruvberger, C., Christensen, T.H., Hansen, T.L. and Jansen, J.1.C., 2007. Methane yield in source-sorted organic fraction of municipal solid waste. Waste Management 27, 406-414.

De Boever, J.L., Cottyn, B.G., De Brabander, D.L., Vanacker, J.M. and Boucqué, C.V., 1996. Prediction of the feeding value of grass silages by chemical parameters, in vitro digestibility and near-infrared reflectance spectroscopy. Anim. feed sci. technol. 60, 103-115.

Feller, C., Jeanson, P., Giummelly, P., Bonaly, P., 1991. Comparaison de différentes méthodes d'hydrolyse acide en vue du dosage des glucides totaux dans les sols. Sci. sol 29, 13-22. 
Gorretta, N., Roger, J.M., Aubert, M., Bellon-Maurel, V., Campan, F. and Roumet, P., 2006. Determining vitreousness of durum wheat kernels using near infrared hyperspectral imaging. J. near infrared spectrosc. 14, 231-239.

Gunaseelan, V.N., 2007. Regression models of ultimate methane yields of fruits and vegetable solid wastes, sorghum and napiergrass on chemical composition. Bioresour. technol. 98, 12701277.

Gunaseelan, V.N., 2009. Predicting ultimate methane yields of Jatropha curcus and Morus indica from their chemical composition. Bioresour. technol. 100, 3426-3429.

Hansen, T.L., Schmidt, J.E., Angelidaki, I., Marca, E., Jansen, J.1.C., Mosbaek, H. and Christensen, T.H., 2004. Method for determination of methane potentials of solid organic waste. Waste Management 24, 393-400.

Jacobi, H.F., Moschner, C.R., Hartung, E., 2009. Use of near infrared spectroscopy in monitoring of volatile fatty acids in anaerobic digestion. Water sci. technol. 2, 339-346.

Lesteur, M., Bellon-Maurel, V., Gonzalez, C., Latrille, E., Roger, J.M., Junqua, G. and Steyer, J.P., 2010. Alternative methods for determining anaerobic biodegradability: A review. Process Biochem. 45, 431-440.

Leyva, A., Quintana, A., Sánchez, M., Rodríguez, E.N., Cremata, J., Sánchez, J.C., 2008. Rapid and sensitive anthrone-sulfuric acid assay in microplate format to quantify carbohydrate in biopharmaceutical products: Method development and validation. Biologicals 36, 134-141.

Mottet, A., François, E., Latrille, E., Steyer, J.P., Déléris, S., Vedrenne, F., Carrère, H., 2010. Estimating anaerobic biodegradability indicators for waste activated sludge. Chem. eng. j. Article in Press. doi:10.1016/j.cej.2010.03.059

Piccolo, A., Zena, A., Conte, P., 1996. A comparison of acid hydrolyses for the determination of carbohydrate content in soils. Commun. soil sci. plant anal. 27, 2909-2915.

Ras, M. , Girbal-Neuhauser, E., Paul, E., Spérandio, M., Lefebvre, D. 2008. Protein extraction from activated sludge: An analytical approach. Water res. 42: 1867-1878.

Rodriguez, C., Hiligsmann, S., Ongena, M., Charlier, R. and Thonart, P., 2005. Development of an enzymatic assay for the determination of cellulose bioavailability in municipal solid waste. Biodegradation 16, 415-422.

Roger, J.M. and Bellon-Maurel, V., 2000. Using genetic algorithms to select wavelengths in near-infrared spectra: Application to sugar content prediction in cherries. Appl. spectrosc. 54, 1313-1320.

Savitsky, A., and Golay, M.J.E., 1964. Smoothing and Differentiation of Data by Simplified Least Squares Procedures. Anal. Chem. 36, 1627-1639. 
Scaglia, B., Confalonieri, R., D'Imporzano, G. and Adani, F., 2010. Estimating biogas production of biologically treated municipal solid waste. Bioresour. technol. 101, 945-952.

Schievano, A., Scaglia, B., D'Imporzano, G., Malagutti, L., Gozzi, A., Adani, F., 2009. Prediction of biogas potentials using quick laboratory analyses: Upgrading previous models for application to heterogeneous organic matrices. Bioresour technol. 100, 5777-5782.

Stuth, J., Jama, A. and Tolleson, D., 2003. Direct and indirect means of predicting forage quality through near infrared reflectance spectroscopy. Field crops res. 84, 45-56.

Van Der Voet, H., 1999. Pseudo-degrees of freedom for complex predictive models: the example of partial least square. J. chemometrics 13, 195-208.

Van Soest, P.J., Robertson, J.B., Lewis, B.A., 1991. Methods for dietary fiber, neutral detergent fiber, and nonstarch polysaccharides in relation to animal nutrition. J. dairy sci. 74, 3583-3597.

VIM - International Vocabulary of Metrology - Basic and General Concepts and Associated Terms. JCGM/WG 2 Document N318, $3^{\text {rd }}$ edition, Final draft 2006-08-01

Viscarra Rossel, R.A., Walvoort, D.J.J., McBratney, A.B., Janik, L.J. and Skjemstad, J.O., 2006. Visible, near infrared, mid infrared or combined diffuse reflectance spectroscopy for simultaneous assessment of various soil properties. Geoderma 131, 59-75.

Widmer-Girod, C., Staub, C., 2004. Measurement uncertainty : to be define in forensic toxicology. Ann. Toxicol. Anal. 16, 215-219.

Williams, P.C., and Sobering, D.C., 1993. Comparison of commercial near infrared transmittance and reflectance instruments for analysis of whole grains and seeds. J. near infrared spectrosc. 1, 25-32.

Williams, P. and Noris, K. 2001. Near-Infrared Technology in the Agricultural and Food Industries, 2nd Edition, Amer Assn of Cereal Chemists, St. Paul, Minnesota, USA.

Zeaiter, M., Roger, J.M. and Bellon-Maurel, V., 2005. Robustness of models developed by multivariate calibration. Part II: The influence of pre-processing methods. TrAC, Trends anal. chem. 24, 437-445.

Zhang, L., Garcia-Munoz, S., 2009. A comparaison of different methods to estimate prediction uncertainty using Partial Least Squares (PLS): A practitioner's perspective. Chemometr. intell. lab. syst. 97, 152-158. 